\title{
Public benefit and risk perceptions of nanotechnology development: Psychological and sociological aspects
}

\author{
Nur Aizat Kamarulzaman ${ }^{\text {a }}$, Khai Ern Lee ${ }^{\text {a,b,c, * }}$, Kim Shyong Siow ${ }^{\text {d }}$, Mazlin Mokhtar ${ }^{\text {a,c }}$ \\ ${ }^{a}$ Research Centre for Sustainability Science \& Governance (SGK), Institute for Environment and Development (LESTARI), Universiti Kebangsaan Malaysia, 43600, UKM \\ Bangi, Selangor, Malaysia \\ ${ }^{\mathrm{b}}$ Centre for Research and Instrumentation Management (CRIM), Universiti Kebangsaan Malaysia, 43600, UKM Bangi, Selangor, Malaysia \\ ${ }^{\mathrm{c}}$ Jeffrey Sachs Center on Sustainable Development, Sunway University, No. 5, Jalan Universiti, Selangor, Malaysia \\ ${ }^{\mathrm{d}}$ Institute of Microengineering and Nanoelectronics (IMEN), Universiti Kebangsaan Malaysia, 43600, UKM Bangi, Selangor, Malaysia
}

\section{A R T I C L E I N F O}

\section{Keywords:}

Nanotechnology

Risk

Benefit

Perception

Psychological

Sociological

Public

\begin{abstract}
A B S T R A C T
Nanotechnology enables the development of new and improved products. However, the public is also concerned about uncertain risks associated with nanotechnology-enabled products. To address this concern, the study aims to expand the understanding about public benefit and risk perceptions as a basis for the effective formulation of policy that addresses public interests. The study investigates public benefit and risk perceptions of nanotechnology development from the psychological and sociological aspects through a questionnaire survey conducted on Klang Valley, Malaysia. Analysis of variance (ANOVA) illustrates that demographics indeed influences public benefit and risk perceptions of nanotechnology development. However, public knowledge about nanotechnology exerts no effect on public benefit and risk perceptions of nanotechnology development based on independent $\mathrm{t}$ tests. Simple linear regression reveals that the lack of public trust in government increases risk perception. Public attitude perceives nanotechnology to be more beneficial than risky, thus influencing benefit perception rather than risk perception. Public lifestyle, such as culture, religious beliefs and social group influence benefit perception but not risk perception. Result is expected to deliver better communication of benefit and risk of nanotechnology to the public as well as ensure an ethical policy regarding nanotechnology development.
\end{abstract}

\section{Introduction}

\subsection{Nanotechnology}

Nanotechnology-enabled products have a long shelf life with improved performance, whereas nanotechnology development not only benefits but also exposes the public to uncertain risks associated with nanotechnology. Despite being well-proven to improve the livelihood of human beings, the public rejects other technologies, such as genetic modification and nuclear energy, due to the lack of inclusion of public benefit and risk perceptions during initial development [1-4]. Hence, public benefit and risk perceptions of nanotechnology development are vital to increase the public's understanding and improve acceptance of emerging technology. Communicating the benefits and risks of nanotechnology is an efficient approach for gaining public trust and preparing the public with appropriate information, which will enable the public to make informed decisions and avoid fear of the unknown due to lack of information [5]. The study focuses on Malaysia, which aspires to promote nanotechnology as one of the country's enablers in driving the economy. Malaysia initiated the Malaysia National Nanotechnology Initiatives (MNNI) in 2006, in which the third MNNI objective is the enhancement of societal and environmental contribution [6]. Hence, understanding public perception of nanotechnology is required to improve public communication on nanotechnology as well as for the effective formation of policy for ethical nanotechnology development. The study aims to shed light on the public benefit and risk perceptions of nanotechnology development based on demographic, psychological and sociological factors. Findings will be useful for inclusive nanotechnology development.

\footnotetext{
* Corresponding author. Research Centre for Sustainability Science \& Governance (SGK), Institute for Environment and Development (LESTARI), Universiti Kebangsaan Malaysia, 43600, UKM Bangi, Selangor, Malaysia.

E-mail address: khaiernlee@ukm.edu.my (K.E. Lee).
} 


\subsection{Public perception}

In general, scientists conduct research in laboratories and kept findings confidential because sharing with the public may jeopardise their career [7]. The public was shielded from the new development in science because such a discovery was reserved for the scientific elite. In recent years, communicating science to the public has become the interest of government and private agencies to educate the public about recent developments in science as the public gained benefits from previous scientific advancements. As the end-user of nanotechnology-enabled products, the public will be affected by uncertain risks of technology development; hence, the strong desire for familiarity with the latest development. From another perspective, scientists are cautious about sharing results with the general public because they prefer the results to be published before being publicised [8]. The reason for this notion is that journal publication has been proven a more credible dissemination channel compared with media coverage. However, understanding journal articles is difficult for the general public. At the same time, the rapid development of science and technology should be communicated continuously, which demands various resources. Thus, a different approach is required for better communication. Fraser and Restrepo-Estrada [9] defined communication for development as 'the use of communication process, techniques and media to help people towards full awareness of their situation and options for change, to resolve conflicts, to work towards consensus, to help people plan actions for change and sustainable development, to help people acquire the knowledge and skills they need to improve their condition, society and effectiveness of institution' [9].

Scientific literacy is defined as 'knowing how science works', thus promoting science to the public for a better understanding of new scientific knowledge [10]. To facilitate the public's understanding of science in a new way of communicating, familiarity with controversial facts, theories and issues is necessary [10]. The public should be duly informed about the potentials and limitations of science, where public communication opens up a space for the public to think critically to better solve problems [11]. A lesson can be learned from the science and technology communication of biotechnology at a time when the European public opposed biotechnology in the late 1970s because of potential risks emerging from agricultural biotechnology [12]. This concern was further exacerbated by new food technologies, such as mad cow disease and genetically modified organisms [13]. The advocacy to communicate science and technology to the public was based on the assumption that the public that understood science will support it [14]. However, for decades, the public was informed about technology development only after the technology has been developed $[7,15]$. Furthermore, public communication was based on a one-way communication setting. Information about technology was provided through an educational approach to improve public understanding [16]. Although the public was included and many educational programmes were established, the one-way communication approach has created a knowledge gap between layperson and experts $[17,18]$. Hitherto, the public remained highly sceptical about agricultural biotechnology, and their acceptance has not increased [10].

Nanotechnology emerges and requires a different approach in public communication to avoid backlash. One of the main factors that shape public communication for nanotechnology is lessons learned from controversial technologies [19-21]. Communication for nanotechnology involves interaction among various stakeholders, such as government agencies, industries and researchers, by engaging the public in decision making, which is essential for policy development [22]. Public deliberation involving two-way communication is introduced to articulate the social and ethical implications of nanotechnology that promises a paradigm shift in science and technology communication [23]. However, Kurath and Gisler [22] argued that the traditional approach is still in practice in the public deliberation of nanotechnology, which fails to reflect the critical impacts of the results of policymaking, and is only limited to values on the social and ethical aspects. Increased knowledge and awareness gained from deliberation do not improve the public scepticism for government and industries in regulating nanotechnology to represent public interests $[23,24]$. Hence, understanding factors that influence public perception is vital for the development of effective policy [25], which will be instrumental for the ethical management of nanotechnology. In this regard, the study uses demographic, psychological and sociological aspects to understand the benefit and risk perceptions of nanotechnology development.

\subsection{Factors influencing public perception}

\subsubsection{Demographics}

Various studies have been conducted to investigate how demographics influence public perceptions. The current study takes into account different demographic factors to investigate their influence on the public benefit and risk perceptions of nanotechnology. Pilisuk and Acredolo [26] proposed that well-educated individuals consider technological hazards as less risky than others due to a better comprehension of types of hazards. Socio-demographics has been illustrated to influence risk perception, whereas the poor, ethnic minorities and women tend to reject new technology due to high levels of risk perception [27]. Compared with their counterparts, affluent and well-educated individuals with a better understanding of science afford better protection from technology hazards through financial means. Thus, such people perceive technology as more beneficial and show high levels of acceptance of technological improvement [26]. Ethnic minorities are warier about technological risks [27-29] as they may be trapped in poverty, which prevents them from obtaining better education [30]. Women have a high risk perception of technology than men because women are more vulnerable than men. Therefore, women are more alert to perceived risks [31]. Alternatively, Cobb and Macoubrie [32] found that educated individuals perceive nanotechnology as bringing more benefits than risks. Male, youth and educated individuals are groups that are optimistic about nanotechnology benefits vis-à-vis risks [33]. As previously mentioned, women perceive high risk in technology, in which they show a similar concern towards nanotechnology [34]. Thus, women display low levels of willingness to buy nanotechnology-enabled products [35]. Furthermore, the public over the age of 48 years and under 36 years are less concerned about nanotechnology compared with other age groups [36]. Therefore, the study presents the following hypothesis for demographics in influencing public perception towards nanotechnology.

H1. Risk perception is higher for women, aged individuals, minorities and low-income groups compared with their counterparts.

Moreover, the study introduces psychological and sociological aspects to further understand the public perception of nanotechnology. Knowledge, attitudes and trust are grouped under the psychological aspect, whereas the sociological aspect pertains to the public's lifestyle, which includes culture, religion and social groups [37].

\subsubsection{Psychological aspects}

Various levels of knowledge between the public and experts resulted in different perceptions of nanotechnology [34,38]. Although both groups agree that the benefit outweighs the risk, however, the public displays high levels of risk perception. Comprehensive knowledge about nanotechnology enables a person to perceive nanotechnology as beneficial and thus willing to accept the risk of nanotechnology [39-42]. The notion indicates that not all risks are unacceptable; however, risks associated with benefits are more acceptable [43]. Knowledge possessed by experts give the confidence that risks will not directly harm the public [34]. Furthermore, experts' experience, knowledge and expertise in handling nanotechnology enable them to view the development of nanotechnology in a controlled manner, thus resulting in their lower risk perception than the public [37]. However, experts' concerns focus on 
the 'new pollution' and 'new disease' that may arise from future nanotechnology-enabled products [38]. Conversely, the general public has limited and different knowledge than experts. The public obtains knowledge about technology by relying on risks associated with a particular technology [44]. Furthermore, their familiarity with nanotechnology is dependent on the amount of information they gather from media coverage. Hence, the following hypothesis for knowledge in influencing public perception towards nanotechnology is presented.

H2. The public familiar with nanotechnology has high levels of benefit perception of nanotechnology.

Trust in the government, researchers and industries encourage the public to make decisions based on information received about nanotechnology [45]. Policy can also be easily formed with the trust afforded by the public [46]. Siegrist et al. [34] observed that experts rely to the government to handle nanotechnology and protect society from risks. The authors also suggested that high levels of trust in the government, researchers and industries increase benefit perception and thus decrease risk perception towards nanotechnology. Although civil society depends on how the government, researchers and industries manage risks associated with nanotechnology, the public also tends to be hesitant and anxious of the possible impacts of nanotechnology. Citizens who trust government agencies, such as the Food and Drug Administration will continue to trust the government to prioritise the interest of the public by providing information about nanotechnology in labelling and possibly establishing mandatory labelling for future products [47]. Trust is essential for policymakers to manage the public's concerns and abilities to develop nanotechnology in the direction aligned with public interests. Hence, the following hypothesis for public trust is formulated:

H3. Trust in the government, researchers and industries will increase the public's benefit perception.

Attitude serves as a heuristic signal when one recalls past behaviours and influences present judgements and decisions [48-50]. Information received is defined differently according to an individual's background. For example, a person will decide whether to accept information based on their memory of such information. Heuristic attitudes are defined as 'evaluative relationships in which one uses an object as a strategy to solve the problem by determining whether the object is in a preferred category, i.e. a strategy of liking and protecting, or being in an unwanted category, a strategy of hate and harm' [49]. Moreover, attitude towards nanotechnology is defined as 'the positive or negative attitudes of society towards nanotechnology dependent on the perceived benefits and risks of nanotechnology applications by individuals' [45,51]. The public with a positive attitude towards science and technology and has never encountered a bad experience in this regard will perceive nanotechnology as beneficial. As such, they possess a positive attitude towards nanotechnology. In contrast, the public with controversial issues regarding science and technology will perceive nanotechnology as risky and likely to reject nanotechnology [52]. Thus, the study proposes the following hypothesis for attitude.

H4. A positive attitude towards nanotechnology decreases the risk perception of nanotechnology.

\subsubsection{Sociological aspects}

Previous studies also pointed out the sociological aspects of influencing public perception. An individual's way of life is a combination of cultural values (i.e. shared values and beliefs) and social relationships (i. e. human relationships) [53]. In addition, culture is defined as a lifestyle that contains values and beliefs inherited by younger generations from older generations [54]. These generational views are also shaped by social groups, such as organisations and peers [55]. In this regard, the public thus aims to learn and understand their culture to decide whether a product or technology is beneficial or risky and act accordingly based on their cultural values [56].
Furthermore, technology policy embedded in culture prepares the public in terms of familiarity with technology development [57]. Thus, a culture that values technology will embrace technology in general. Therefore, the hypothesis for culture is formulated as follows.

H5. Individuals that are culturally familiar with science and technology display a high benefit perception of nanotechnology.

Religion is a value system that individuals use to understand new facts, including science and technology. To a certain extent, acceptance of technology varies depending on religiosity. People with strong religious beliefs are morally disproportionate with nanotechnology compared to those with less faith in their religion. Science and religion are components of the cultural process in society [58]. Benefit perception of nanotechnology is found among individuals with less religion-learning and living in a secular society. As a moral issue, technology draws attention from the broader society that holds religious beliefs because technology interferes with the natural processes of nature. Hence, this scenario is considered risky and morally unacceptable [59]. In addition, communities that hold strong faith are likely to support funding for research and development of nanotechnology [40] as they believe that technology is associated with 'playing God'. Thus, the study presents the hypothesis for religious lifestyle as follows.

H6. Religious beliefs influence the public to display high levels of risk perception of nanotechnology.

Sociological aspects involve the benefit and risk perceptions of social groups regarding nanotechnology depending on the impact of technology $[37,60]$. A social group is defined as a group of individuals with similar aims and collective unity. Public concern on nanotechnology is focused not only on toxicological risks but also the extent of benefits and risks of nanotechnology in manufacturing and production, distribution, use, and disposal of nano-products that may be experienced only by particular social groups [61]. This coverage leads to a perception of nanotechnology that involves the equal distribution of nanotechnology to different social groups. Inequality in distributing the benefits and risks of nanotechnology among social groups may lead to more exposure to risks for others. Furthermore, social groups with varying levels of knowledge about nanotechnology may have different interpretations of benefits and risks based on their technical skills in handling technology [62]. In addition, different social groups will hold perceptions depending on how technology benefits them and how risks are addressed. In this situation, social trust is best suited for a society that lacks capacity, knowledge, interests and resources. Social trust is defined as 'the willingness to rely on those who have the responsibility for making decisions and taking actions related to the management of technology, the environment, medicine, or other realms of public health and safety' [63]. Therefore, public acceptance of new technology is reliant on information provided and social trust guided by the government, researchers and industries $[32,63,64]$. In this context, funding on nanotechnology development is crucial for research to ensure the fair distribution of the benefits of nanotechnology and protect social groups from risks [60]. Hence, the following hypothesis regarding the impact of funding for nanotechnology development on social groups is presented.

H7. The impact of funding for nanotechnology development on social groups increases risk perception.

\section{Methods}

\subsection{Survey}

The study was conducted in Klang Valley, Malaysia from April to June 2017 based on an estimated population of 8.18 million. Klang Valley is the most populated area in Malaysia with the aspiration to be developed as a hub for nanotechnology due to the density of various government agencies, non-governmental organisations, universities and 
research centres in this area. The study focuses on three main ethnic groups in Malaysia, namely, Malay (67.4\%), Chinese (24.6\%) and Indian (7.3\%) [65]. Questionnaires were distributed in person to 407 respondents among the ten (10) city councils. The respondents represent different demographic groups in terms of gender, age, ethnicity, level of education and household income. Reliability of the measurement of factors in influencing benefit and risk perceptions was measured using Cronbach's alpha $(\alpha)$.

\subsection{Independent variables (psychological aspects)}

\subsubsection{Knowledge}

Knowledge about nanotechnology was a binary variable and measured as No $=0$ and Yes $=1$. Those who answered 'Yes' were requested to answer the follow-up questions about nanotechnology applications to further test their familiarity.

\subsubsection{Attitude}

Attitude was measured using three questions, namely, 'What is your opinion on the benefit of nanotechnology?', 'Do you agree with using nanotechnology application in consumer products?' and 'Are you willing to buy nanotechnology products?' The questions were adapted from Kishimoto [66] with a few modification to suit the objective of the current study. The means of the three questions were summed and averaged to represent attitude $(1=$ strongly disagree, $7=$ strongly agree; $\mathrm{M}=4.85, \mathrm{SD}=1.01, \alpha=0.88)$.

\subsubsection{Trust}

Four items rated from $1=$ less trustful to $7=$ most trustful were used to measure trust in the government $(M=4.43, S D=1.33, \alpha=0.94)$, researchers $(\mathrm{M}=5.04, \mathrm{SD}=1.21, \alpha=0.96)$ and industries $(\mathrm{M}=4.64$, $\mathrm{SD}=1.07, \alpha=0.94)$.

\subsection{Independent variables (sociological aspects)}

\subsubsection{Public lifestyle (culture, religious beliefs and social groups)}

Three items were rated from 1 = strongly disagree to $7=$ strongly agree to measure culture, religious beliefs and social groups. The items are 'Based on your lifestyle, do you well accept nanotechnology?' ( $M=$ 4.86 , SD $=1.16$ ), 'Based on your religion, do you well accept nanotechnology?' ( $\mathrm{M}=4.90, \mathrm{SD}=1.19)$ and 'Based on your lifestyle and religion, do you support funding for nanotechnology research?' ( $\mathrm{M}=$ $5.20, \mathrm{SD}=1.20$ ) with Cronbach's $\alpha=0.96$.

\subsection{Dependent variables}

\subsubsection{Benefit and risk perceptions of nanotechnology}

Twelve items were used to measure benefit and risk perceptions of nanotechnology. Benefit perception is a summative index of six items that assesses the perceived benefits of applying nanotechnology in cosmetics, electrical appliances, medicine, food, sports equipment, detergent, nano-therapy, nano-pesticides and nano-fertilisers $(1=$ less beneficial, $7=$ most beneficial; $\mathrm{M}=4.82, \mathrm{SD}=0.82, \alpha=0.84)$. Alternatively, risk perception is a summative index of six items regarding the risks of applying nanotechnology in the abovementioned categories ( 1 $=$ less risky, $7=$ most risky; $\mathrm{M}=4.51, \mathrm{SD}=0.92, \alpha=0.88$ ).

\section{Analysis}

Analysis of variance (ANOVA) was conducted on the respondents' demographics followed by a post-hoc test to determine the significant difference between demographic factors in influencing public benefit and risk perceptions. Furthermore, an independent $t$-test was conducted to test public benefit and risk perceptions as influenced by knowledge. A simple linear regression was performed to test the influence of attitude, trust, culture, religious beliefs and social groups on public perception.

\section{Results}

Table 1 provides a descriptive analysis of respondents' demographic, psychological and sociological aspects as well as the public benefit and risk perceptions of nanotechnology. The majority of the respondents are female $(63.9 \%)$ and belong to the age group between 21 and 40 years, Malay (68.1\%), bachelor degree holders (37.3\%), and earn RM3000 and below $(38.8 \%)$. In terms of psychological aspects, $47.2 \%$ of the

Table 1

Descriptive analysis.

\begin{tabular}{|c|c|c|c|}
\hline Variables & Percentage & $\mathrm{M}$ & SD \\
\hline Independent variables & & - & - \\
\hline Demographic & & - & - \\
\hline Gender & Female (63.9) & - & - \\
\hline Age & & - & - \\
\hline 18 to 20 (Adolescent) & 7.4 & - & - \\
\hline 21 to 40 (Young adult) & 85.0 & - & - \\
\hline 41 to 51 (Middle-age adult) & 7.6 & - & - \\
\hline Ethnic & & - & - \\
\hline Malay & 68.1 & - & - \\
\hline Chinese & 19.7 & - & - \\
\hline Indian & 10.1 & - & - \\
\hline Education & & - & - \\
\hline $\begin{array}{l}\text { Malaysia Lower Certificate of } \\
\text { Education (LCE) }\end{array}$ & 2.2 & - & - \\
\hline $\begin{array}{l}\text { Malaysian Certificate of Education } \\
\text { (MCE) }\end{array}$ & 17.2 & - & - \\
\hline Matriculation & 5.2 & - & - \\
\hline Diploma & 20.4 & - & - \\
\hline Bachelor degree & 37.3 & - & - \\
\hline Master degree & 15.0 & - & - \\
\hline Ph.D. & 2.7 & - & - \\
\hline Household income & & - & - \\
\hline$\leq \mathrm{RM} 1000$ & 5.4 & - & - \\
\hline$\leq \mathrm{RM} 3000$ & 38.8 & - & - \\
\hline$\leq$ RM5000 & 31.2 & - & - \\
\hline$\leq$ RM7000 & 10.3 & - & - \\
\hline$\leq \mathrm{RM} 9000$ & 5.4 & - & - \\
\hline$>$ RM9001 & 8.8 & - & - \\
\hline $\begin{array}{l}\text { Independent variable } \\
\text { (psychological approach) }\end{array}$ & & - & - \\
\hline Knowledge about nanotechnology & $\begin{array}{l}47.2 \% \text { (unaware about } \\
\text { nanotechnology) }\end{array}$ & - & - \\
\hline Attitude towards nanotechnology & - & 4.85 & 1.01 \\
\hline $\begin{array}{l}\text { Trust in government on } \\
\text { nanotechnology development }\end{array}$ & - & 4.47 & 1.33 \\
\hline $\begin{array}{l}\text { Trust in researchers on } \\
\text { nanotechnology development }\end{array}$ & - & 5.04 & 1.21 \\
\hline $\begin{array}{l}\text { Trust in industries on } \\
\text { nanotechnology development }\end{array}$ & - & 4.63 & 1.07 \\
\hline $\begin{array}{l}\text { Independent variables (sociological } \\
\text { approach) }\end{array}$ & - & & \\
\hline Culturally accept nanotechnology & - & 4.86 & 1.16 \\
\hline $\begin{array}{l}\text { Religious beliefs on accepting } \\
\text { nanotechnology }\end{array}$ & - & 4.90 & 1.19 \\
\hline $\begin{array}{l}\text { Socially accept research funding of } \\
\text { nanotechnology }\end{array}$ & - & 4.88 & 1.13 \\
\hline Dependent variables & - & & \\
\hline $\begin{array}{l}\text { Benefit perception of } \\
\text { nanotechnology }\end{array}$ & - & 4.82 & 0.82 \\
\hline \multicolumn{4}{|l|}{ Nano-application (benefit) } \\
\hline Cosmetic & - & 4.86 & 1.43 \\
\hline Electrical appliances & - & 4.99 & 1.44 \\
\hline Medical & - & 5.40 & 1.40 \\
\hline Food & - & 4.40 & 1.61 \\
\hline Sport equipment & - & 4.64 & 1.50 \\
\hline Detergent & - & 5.20 & 1.35 \\
\hline \multicolumn{4}{|l|}{ Nano-application (risk) } \\
\hline Cosmetic & - & 4.37 & 1.46 \\
\hline Electrical appliances & - & 3.94 & 1.47 \\
\hline Medical & - & 4.28 & 1.55 \\
\hline Food & - & 4.79 & 1.67 \\
\hline Sport equipment & - & 3.62 & 1.52 \\
\hline Detergent & - & 3.90 & 1.52 \\
\hline
\end{tabular}


respondents are unaware about nanotechnology. In general, public attitude is positive $(M=4.85, S D=1.01)$. The respondents indicated high levels of trust in researchers $(M=5.04$. $S D=1.21)$, industries $(M=$ $4.63, \mathrm{SD}=1.07)$ and the government $(\mathrm{M}=4.47, \mathrm{SD}=1.33)$. In terms of culture and religious beliefs, the public is accepting nanotechnology and agree with funding the research on nanotechnology (culture: $\mathrm{M}=4.86$, $\mathrm{SD}=1.16$; religious beliefs: $\mathrm{M}=4.90, \mathrm{SD}=1.19$; funding: $\mathrm{M}=4.88, \mathrm{SD}$ $=1.13$ ). The science and technology policy that has been introduced in 1986 to the Malaysian public may induce their acceptance towards nanotechnology. The public perceives nanotechnology as slightly more beneficial than risky (benefit perception: $\mathrm{M}=4.82, \mathrm{SD}=0.82$; risk perception: $\mathrm{M}=4.51, \mathrm{SD}=0.92$ ).

\subsection{Benefit perception influenced by demographics}

Table 2 displays the ANOVA for demographics in influencing benefit perception, whereas Table 3 shows the post-hoc test. Table 2 shows significant differences for ethnicity and level of education in influencing benefit perception. Moreover, Table 3 shows significant differences between Malay and Chinese and levels of education of MCE and LCE, Diploma, Bachelor and Master degrees. Compared with the Chinese, the Malay is found to perceive nanotechnology as more beneficial (Malay: $\mathrm{M}=4.88, \mathrm{SD}=0.82$; Chinese: $\mathrm{M}=4.55, \mathrm{SD}=0.85$ ). This difference may be due to the fact that the Chinese is more careful when dealing with new technology compared with the Malay [67]. Respondents with high levels of education perceive nanotechnology as more beneficial (Masters: $\mathrm{M}=4.99, \mathrm{SD}=0.76$; Bachelors:, $\mathrm{M}=4.97, \mathrm{SD}=0.84$; Diploma: $\mathrm{M}=4,75, \mathrm{SD}=0.68$; $\mathrm{MCE}: \mathrm{M}=4.67, \mathrm{SD}=0.77$ ) compared with $\mathrm{LCE}(\mathrm{M}=3.82, \mathrm{SD}=0.90)$. This finding is in agreement with the author in Ref. [68], who proposed that highly educated individuals show less concern about nanotechnology.

\subsection{Risk perception influenced by demographics}

Table 4 shows that risk perception is influenced by respondents' demographics, whereas Table 5 presents the results of the post-hoc test. Table 4 reveals that age, ethnicity, level of education and household

Table 2

Benefit perception influenced by demographics.

\begin{tabular}{lllll}
\hline Demographics & $\mathrm{M}$ & $\mathrm{SD}$ & Levene's test & P-value ANOVA \\
\hline Gender & & & & \\
Men & 4.76 & 0.75 & 0.100 & 0.261 (Independent $t$ - \\
Women & 4.86 & 0.85 & & test) \\
Age & & & & 0.536 \\
18 to 20 & 4.97 & 0.80 & 0.256 & \\
21 to 40 & 4.82 & 0.83 & & \\
41 to 51 & 4.74 & 0.68 & & $0.003^{*}$ \\
Ethnic & & & & \\
Malay & 4.88 & 0.82 & 0.011 & \\
Chinese & 4.55 & 0.85 & & $0.000^{*}$ \\
Indian & 4.83 & 0.62 & & \\
Education & & & & \\
LCE & 3.82 & 0.90 & 0.019 & \\
MCE & 4.67 & 0.78 & & \\
Matriculation & 4.57 & 0.85 & & \\
Diploma & 4.75 & 0.68 & & \\
Degree & 4.97 & 0.84 & & \\
Master degree & 4.99 & 0.76 & & \\
Ph.D. & 4.68 & 1.15 & & \\
Household income & & & & \\
Below RM1000 & 4.64 & 0.80 & 0.000 & \\
RM1001-RM3000 & 4.78 & 0.90 & & \\
RM3001-RM5000 & 4.81 & 0.79 & & \\
RM5001-RM7000 & 5.14 & 0.55 & & \\
RM7001-RM9000 & 4.63 & 0.99 & & \\
RM9001 and above & 4.91 & 0.59 & & \\
\hline
\end{tabular}

Note: a) Age $\mathrm{F}(2,404)=0.624$, b) Ethnic $\mathrm{F}(4,402)=4.074$, c) Education $\mathrm{F}$ $(6,400)=4.669$, d) Household income $F(5,401)=1.969$.
Table 3

Post-hoc Tukey HSD for benefit perception.

\begin{tabular}{ll}
\hline Demographics & Benefit Perception \\
\hline Ethnic & \\
Malay & $4.88^{\mathrm{a}}$ \\
Chinese & $4.55^{\mathrm{b}}$ \\
Indian & $4.83^{\mathrm{ab}}$ \\
Education & \\
LCE & $3.82^{\mathrm{a}}$ \\
MCE & $4.67^{\mathrm{b}}$ \\
Matriculation & $4.57^{\mathrm{b}}$ \\
Diploma & $4.75^{\mathrm{b}}$ \\
Degree & $4.97^{\mathrm{b}}$ \\
Master degree & $4.99^{\mathrm{b}}$ \\
Ph.D. & $4.68^{\mathrm{ab}}$ \\
\hline
\end{tabular}

Note: Values with the same superscript character are not significantly different in Tukey HSD.

Table 4

Risk perception influenced by demographics.

\begin{tabular}{lllll}
\hline Demographics & M & SD & Levene's test & P-value ANOVA \\
\hline Gender & & & & \\
Men & 4.48 & 0.83 & 0.023 & $\begin{array}{l}0.665 \text { (Independent } t \text { - } \\
\text { test) }\end{array}$ \\
Women & 4.52 & 0.97 & & \\
Age & & & & $0.001^{*}$ \\
18 to 20 & 3.93 & 1.18 & 0.052 & \\
21 to 40 & 4.54 & 0.89 & & \\
41 to 51 & 4.68 & 0.79 & & $0.012^{*}$ \\
Ethnic & & & & \\
Malay & 4.46 & 0.93 & 0.028 & \\
Chinese & 4.54 & 0.97 & & $0.001^{*}$ \\
Indian & 4.91 & 0.68 & & \\
Education & & & & \\
LCE & 3.95 & 0.69 & 0.000 & \\
MCE & 4.32 & 1.07 & & \\
Matriculation & 4.89 & 0.28 & & \\
Diploma & 4.56 & 0.88 & & \\
Degree & 4.62 & 0.93 & & \\
Master degree & 4.48 & 0.86 & & \\
Ph.D. & 3.69 & 0.66 & & \\
Household income & & & & \\
Below RM1000 & 4.57 & 0.92 & 0.028 & \\
RM1001-RM3000 & 4.37 & 1.03 & & \\
RM3001-RM5000 & 4.66 & 0.82 & & \\
RM5001-RM7000 & 4.86 & 0.80 & & \\
RM7001-RM9000 & 4.47 & 0.99 & & \\
RM9001 and above & 4.17 & 0.62 & & \\
\hline
\end{tabular}

Note: a) Age $\mathrm{F}(2,404)=7.051, \mathrm{~b})$ Ethnic $\mathrm{F}(4,402)=3.269$, c) Education $\mathrm{F}$ $(6,400)=3.664$, d) Household income $F(5,401)=3.769$.

income significantly influence risk perception of nanotechnology. Significant differences are found between respondents in terms of age groups (18-21, 21 to 40 and 41 to 51). Older respondents are more cautious than younger ones [69] which makes them perceive high levels of risk in nanotechnology (41-51 years: $\mathrm{M}=4.68, \mathrm{SD}=0.79 ; 21-40$ years: $\mathrm{M}=4.54, \mathrm{SD}=0.89 ; 18-20$ years: $\mathrm{M}=3.93, \mathrm{SD}=1.18)$. Respondents with different ethnicity, levels of education and household income also show significant differences in perceiving nanotechnology risks. The Indian perceives nanotechnology as riskier than the Malay (Indian: $\mathrm{M}=4.91, \mathrm{SD}=0.68$; Malay: $\mathrm{M}=4.46, \mathrm{SD}=0.93$ ). In addition, the Malay has a different perception of risk as they are more secured as the majority of the Malaysian population.

In addition, respondents with a Ph.D. qualification show low levels of risk perception compared with matriculation, Diploma and Master's degree holders (Ph.D.: $\mathrm{M}=3.69$, $\mathrm{SD}=0.66$; matriculation: $\mathrm{M}=4.89$, SD 0.28 ; Diploma: $\mathrm{M}=4.56, \mathrm{SD}=0.88$; Bachelor's degree: $\mathrm{M}=4.62, \mathrm{SD}=$ 0.93). Individuals with high levels of education are more confident that the authorities can manage the risk of nanotechnology applications in terms of public health and the environment [70]. Household income shows a significant difference between respondents earning RM1001 to 
Table 5

Post-hoc Tukey HSD for risk perception.

\begin{tabular}{ll}
\hline Demographics & Risk Perception \\
\hline Age & \\
$18-20$ & $3.93^{\mathrm{a}}$ \\
$21-40$ & $4.54^{\mathrm{b}}$ \\
$41-51$ & $4.68^{\mathrm{b}}$ \\
Ethnic & \\
Malay & $4.46^{\mathrm{a}}$ \\
Chinese & $4.54^{\mathrm{ab}}$ \\
Indian & $4.91^{\mathrm{b}}$ \\
Education & \\
LCE & $3.95^{\mathrm{ab}}$ \\
MCE & $4.32^{\mathrm{ab}}$ \\
Matriculation & $4.89^{\mathrm{b}}$ \\
Diploma & $4.56^{\mathrm{b}}$ \\
Degree & $4.62^{\mathrm{b}}$ \\
Master degree & $4.48^{\mathrm{ab}}$ \\
Ph.D. & $3.69^{\mathrm{a}}$ \\
Household income & \\
Below RM1000 & $4.57^{\mathrm{abcd}}$ \\
RM1001-RM3000 & $4.37^{\mathrm{a}}$ \\
RM3001-RM5000 & $4.66^{\mathrm{ad}}$ \\
RM5001-RM7000 & $4.86^{\mathrm{b}}$ \\
RM7001-RM9000 & $4.47^{\mathrm{abcd}}$ \\
RM9001 above & $4.17^{\mathrm{ac}}$ \\
\hline
\end{tabular}

Note: Values with the same superscript character are not significantly different in Tukey HSD.

RM3000 $(\mathrm{M}=4.37, \mathrm{SD}=1.03)$ and RM5001 to RM7000 $(\mathrm{M}=4.86, \mathrm{SD}$ $=0.80$ ). In addition, the low-income group holds low levels of risk perception because they are less likely able to buy or use nanotechnology products, which tend to be expensive $[66,67]$. Therefore, these groups may not be exposed directly to the hazard of nanomaterials. In contrast, high-income respondents earning RM9001 and above shows low levels of risk perception $(M=4.17, S D=0.62)$ than those earning RM3001 to RM5000 (M = 4.66, SD = 0.82) and RM5001 to RM7000. This difference may be attributed to the ability of high-income individuals to have additional options in selecting products and services. In summary, ethnicity and level of education influence benefit perception, whereas age, ethnicity, level of education and household income influence the risk perception of nanotechnology. However, gender has no significant effect on the benefit and risk perception of nanotechnology. Hence, $\mathrm{H} 1$ is rejected in terms of gender and income group but supported in terms of age groups and minorities.

\subsection{Psychological and sociological aspects influencing benefit and risk perceptions of nanotechnology}

Table 6 shows the result of the independent $t$-test. Results show that public benefit and risk perceptions are not influenced by familiarity of nanotechnology. Therefore, $\mathrm{H} 2$ is rejected. The simple linear regression for psychological aspects indicates that attitude, trust in government, researchers and industries influence benefit perception. The public holds a positive attitude towards nanotechnology, as shown in Table 1 ( $\mathrm{min}=$ $4.85, \mathrm{SD}=1.01)$, which increases benefit perception $(\beta=0.635, \mathrm{p}<$ $\left.0.001, R^{2}=0.403\right)$ and decreases risk perception $(\beta=-0.107, \mathrm{p}<0.05$, $\mathrm{R}^{2}=0.012$ ). Hence, $\mathrm{H} 4$ is supported. Trust in government increases benefit and risk perceptions among the public (benefit perception: $\beta=$ 0.364, $\mathrm{p}<0.001, \mathrm{R}^{2}=0.133$; risk perception: $\beta=0.170, \mathrm{p}<0.05, \mathrm{R}^{2}=$ $0.029)$. In contrast, trust in industries influences benefit perception $(\beta=$ $0.410, p<0.001, R^{2}=0.168$ ) but not risk perception. The same result is obtained for trust in researchers (benefit perception: $\beta=0.397, p<$ $\left.0.001, \mathrm{R}^{2}=0.157\right)$. Therefore, H3 is supported, where trust in the government, researchers and industies increase benefit perception. In terms of the sociological aspects, cultural familiarity with technology, religious beliefs and social groups influence benefit perception (culture: $\beta=0.534, \mathrm{p}<0.001, \mathrm{R}^{2}=0.285$; religious beliefs: $\beta=0.604, \mathrm{p}<0.001$, $\mathrm{R}^{2}=0.364$; social groups: $\beta=0.595, \mathrm{p}<0.001, \mathrm{R}^{2}=0.354$ ) but not risk
Table 6

Standardised regression coefficient psychological and sociological aspects influencing benefit and risk perceptions of nanotechnology.

\begin{tabular}{|c|c|c|c|c|c|}
\hline \multicolumn{2}{|c|}{ Independent variables } & \multicolumn{4}{|c|}{ Dependent variables } \\
\hline & & $\mathrm{R}^{2}$ & $\begin{array}{l}\text { Benefit } \\
\text { perception } \\
(\beta)\end{array}$ & $\mathrm{R}^{2}$ & $\begin{array}{l}\text { Risk } \\
\text { perception } \\
(\beta)\end{array}$ \\
\hline \multirow[t]{5}{*}{$\begin{array}{l}\text { Psychological } \\
\text { approach }\end{array}$} & $\begin{array}{l}\text { Knowledge } \\
\text { (independent } \\
\text { t-test) }\end{array}$ & - & -1.140 & - & 1.100 \\
\hline & Attitude & 0.403 & $0.635^{* *}$ & 0.012 & $-0.107^{*}$ \\
\hline & $\begin{array}{l}\text { Trust in } \\
\text { government }\end{array}$ & 0.133 & $0.364 * *$ & 0.029 & $0.170^{*}$ \\
\hline & $\begin{array}{l}\text { Trust in } \\
\text { researchers }\end{array}$ & 0.157 & $0.397^{* *}$ & 0.001 & -0.023 \\
\hline & $\begin{array}{l}\text { Trust in } \\
\text { industries }\end{array}$ & 0.168 & $0.410^{* *}$ & 0.004 & 0.064 \\
\hline \multirow{3}{*}{$\begin{array}{c}\text { Sociological } \\
\text { approach }\end{array}$} & Culture & 0.285 & $0.534 * *$ & 0.001 & -0.033 \\
\hline & $\begin{array}{l}\text { Religious } \\
\text { beliefs }\end{array}$ & 0.364 & $0.604 * *$ & 0.002 & -0.045 \\
\hline & Social groups & 0.354 & $0.595 * *$ & 0.002 & -0.041 \\
\hline
\end{tabular}

$* * \mathrm{p}<0.001 ; * \mathrm{p}<0.05$

perception. Therefore, $\mathrm{H} 5$ is supported, whereas $\mathrm{H} 6$ and $\mathrm{H} 7$ are rejected.

\section{Discussion}

The present study investigates the influence of demographic, psychological and sociological factors on public benefit and risk perceptions, which will be instrumental for the effective formulation of policy that addresses public interests in nanotechnology development. Moreover, effective communication of nanotechnology risks and benefits will help bridge the knowledge gap between experts and the public to enable nanotechnology development and avoid backlash from the public towards emerging technology.

Ethnicity and level of education have shown influences on public benefit and risk perceptions. The majority and minority ethnic groups have different risk perceptions, where the ethnic majority feels more secure. In this regard, ethnic minorities are more concerned about risks [27-29]. The Malay as the ethnic majority is safeguarded by its special position in the Federal Constitution [67], which may result in increased security regarding new technology development. Highly educated individuals have more trust in the government and researchers to protect the public from nanotechnology risks, and therefore perceive more benefits, which is in line with previous research $[32,66]$. Conversely, age and household income only influence risk perception but not benefit perception.

Nevertheless, the study finds no significant influence of gender on public perception, which is inconsistent with the finding of a previous study [31]. This result suggests that demographic factors per se are unable to explain individual differences in public perception of nanotechnology. Another study [71] also suggested other factors to be considered to further understand public perception. Hence, psychological and sociological aspects are taken into account to understand the public perception of nanotechnology.

Results show that the public has limited knowledge about nanotechnology with $47.2 \%$ being unaware about nanotechnology. Knowledge is considered one of the critical factors that contributes to the benefit and risk perceptions of nanotechnology [34]. However, the results show otherwise, as the public experience difficulty in expressing their responses to nanotechnology by stating that they have insufficient knowledge about nanotechnology. A brief explanation was given to the respondents to answer the questionnaire and state their opinions and concerns about the risks associated with nanotechnology [72]. Their perceptions were presented in a heuristic manner through their limited knowledge of science and technology in general, as well as the benefits and risks obtained from various media, including media coverage and 
product labels [73,74]. This limitation urges the future exploration of public knowledge to grasp the public's perception and opinion when it is well informed about nanotechnology. Thus, communicating nanotechnology is of importance to bridge the knowledge gap between the public and experts.

A positive public attitude leads to the benefit perception of nanotechnology, thereby reducing risk perception. Public opinion about nanotechnology is formed by personal experience with other technology and how much information is available to make an informed decision [75]. Arguably, scientific knowledge will result in a positive attitude towards science and technology. However, the informed public is capable in making reasonable and ethical choices with regard to science and technology [76]. Moreover, attitude influences benefit and risk perceptions depending on public benefits or risks perceived in nanotechnology applications [45,51]. The present study found that benefit perception on nanotechnology applications outweighs risk perception. For example, the advantages of nanotechnology applications in the field of medicine for improving the diagnoses and treatments of diseases has elevated benefit perception among the public [77].

Meanwhile, concerns on eating nano-related foods, which may be associated with uncertain health risks raise risk perception. The public will have a better judgement on nanotechnology when they are familiar with products [4]. This familiarity is in line with Frewer et al. [78] and Gupta et al. [79] who illustrated the benefits and risks of nanotechnology applications and their effect on public attitude, which consequently changed their perception of nanotechnology despite perceiving nanotechnology applications as more beneficial than risky.

Trust is an essential factor for the public's acceptance of technology. Compared with other groups, the public has high levels of trust in researchers in terms of providing information on nanotechnology-related benefits and risks, developing nanotechnology following public needs, ensuring public safety from adverse effects of nanotechnology and having enough technical knowledge in managing nanotechnology development. This finding is in line with Lin et al. [80] that the public has more trust in researchers than the government and industries. Trust given by the public to the government, researchers and industries increases public benefit perception of nanotechnology as such stakeholders are the driving forces for the development of nanotechnology. However, finding reveals that the lack of public trust in government compared with the other two stakeholders increases risk perception, although the government is the primary regulator equipped with the necessary authority to manage nanotechnology. Low levels of trust in the government are not caused by the inadequacy of the government to address nanotechnology. However, the public views nanotechnology based on the inefficiency of the government in implementing previous policies [81]. Nevertheless, the public is unaware that various government agencies are collaborating to manage nanotechnology risks, whereas the public only relies on its judgement that the ruling government is not prioritising public needs [82]. Compared to industry and researchers who are not directly involved in national policymaking, researchers gain high levels of trust from the public because the public believes that they will ensure safety from nanotechnology risks through their profound knowledge and skills [66].

In terms of sociological aspects, the public's cultural familiarity with science and technology can be attributed to the introduction of the National Science, Technology and Innovation Policy since 2013-2020, which emphasises science and technology as the economic driver of the well-being of the public. The introduction of the policy has enabled the cultural acceptability of the development of science and technology in general and nanotechnology in particular [83]. Thus, it influences the benefit perception of nanotechnology but not risk perception. In the context of religion, the public perceives nanotechnology as beneficial and not risky. Religiosity acts as a 'filter' of knowledge on nanotechnology when public knowledge is limited, whereas religiosity plays a role in influencing ethical choices $[84,85]$. The development of science and technology emphasising religious ethics [86] creates the foundation for the religious public to accept nanotechnology. Therefore, no technology conflicts with ethics practised in Malaysia, which in turn influences the benefit perception of nanotechnology. However, the study is limited to whether the public is adherent to the practices of their religion. Nevertheless, one research shows that the Malaysian public, despite being highly religious or not, demonstrate a positive perception of nanotechnology [87].

Supporting research funding influences public benefit perception, but not risk perception. As previously mentioned, different public perceptions are obtained across demographics with ethnic minorities, older age groups and middle-income public, which are illustrated to show high levels of risk perception. Public concerns emerge from the unbalanced benefits and risks of nanotechnology that are not shared equally across social groups [61]. In this regard, social groups with high standards of living can enjoy the benefits of nanotechnology. In contrast, those with low standards of living will be left behind. The social implication of unbalanced information distribution, accessibility to nano-applications, inability to gain benefit from nanotechnology, and/or compressed by the risk are essential components to consider during nanotechnology development $[61,68,75,88]$. Supporting nanotechnology research funding is crucial for a more inclusive development to ensure the fair distribution of nanotechnology benefits and avoid uncertain risks by bridging the knowledge gap and promoting beneficial and acceptable nano-applications [89]. Strengthening public communication by reaching out to ethnic minorities, older people and low-income groups are required in the future. Hence, continued research on nanotechnology will enable all social groups to gain benefits as well as be protected from the risks of nanotechnology [90].

\section{Implications of public perception of nanotechnology}

The study serves as a pre-deliberative approach for a better understanding of the public with vested interests and concerns on emerging technology. Previous studies proposed that public participation is vital for improving their understanding of science through deliberation and effective communication [18,91-94]. However, sharing scientific and technological knowledge in a one-way communication approach with the public has shown to be ineffective, thereby causing the 'deficit model'; that is, scientific information is mainly available, but public knowledge is lacking. The social context in the implication of science towards daily public activities is required to communicate science and technology ethically $[95,96]$. Communicating science through dialogues, discussions and debates $[10,97,98]$ that will have an impact on policy is a new means for improving the public's understanding of science.

Results show that the younger individuals have less risk perception than older ones, which suggests nanotechnology should be communicated according to age group, as older individuals have more concerns about nanotechnology. Individuals with low levels of education should also be included using the appropriate approach as the public will seek to know more about nanotechnology if the delivered information is difficult to understand [99]. Individuals in ethnic minority groups and different income levels are groups that are primarily concerned about the implication of nanotechnology, thus calling for continued research to ensure fair distribution of nanotechnology benefits and protection against risks.

The study discussed psychological and sociological factors that can be utilised to understand the current public perception and establish a better deliberation to achieve mutual learning [23,100-103]. Through deliberation with effective communication, the current public perception may be improved with meaningful public engagement [91-95]. In addition, the findings highlight that public trust in stakeholders influence public perception about nanotechnology, especially the government as the primary regulator. Furthermore, public trust in government, researchers and industries will motivate the public to promote practical deliberation, which remains lacking [22], and thus enable effective 
communication about nanotechnology to the public.

\section{Conclusion}

Nanotechnology emerges to address the needs of the public and the desire to improve quality of life. However, opposition to new technology will hinder its potential and undermine its intent due to the misperception of the public, thereby causing significant loss to the sector. The study aimed to understand public perception, which will help to improve nanotechnology communication with the public. Communicating nanotechnology to improve public understanding is important as the public will be influenced by nanotechnology applications, and their decisions will further influence nanotechnology development. One approach to determine the acceptance of nanotechnology is by acknowledging public perception. The study demonstrated that benefit perception is influenced by demographics (ethnicity and level of education), psychological aspects (attitude, trust in government, researchers, and industries) and sociological aspects (culture, religious beliefs and social groups). Although risk perception is influenced by demographics (age, ethnicity, level of education and household income) and psychological aspects (attitude and trust in the government), the findings will benefit stakeholders to further deliberate nanotechnology with the public for effective communication, policy making and ethical nanotechnology management.

\section{CRediT authorship contribution statement}

Nur Aizat Kamarulzaman: Methodology, Formal analysis, Investigation, Writing - original draft. Khai Ern Lee: Conceptualization, Methodology, Validation, Investigation, Resources, Writing - review \& editing, Supervision, Funding acquisition. Kim Shyong Siow: Conceptualization, Investigation, Supervision. Mazlin Mokhtar: Investigation.

\section{Acknowledgement}

The authors would like to acknowledge the financial support for this study provided by Universiti Kebangsaan Malaysia through Dana Impak Perdana (DIP-2015-008) and Geran Universiti Penyelidikan (GUP-2017016).

\section{Appendix A. Supplementary data}

Supplementary data to this article can be found online at https://doi. org/10.1016/j.techsoc.2020.101329.

\section{References}

[1] J.P. Pardo-Guerra, Mapping emergence across the Atlantic: some (tentative) lessons on nanotechnology in Latin America, Technol. Soc. 33 (2011) 94-108, https://doi.org/10.1016/j.techsoc.2011.03.012. Available at:.

[2] V. Chenel, P. Boissy, J.P. Cloarec, J. Patenaude, Effects of disciplinary cultures of researchers and research trainees on the acceptability of nanocarriers for drug delivery in different contexts of use: a mixed-methods study, J. Nanoparticle Res. 17 (2015) 1-17, https://doi.org/10.1007/s11051-015-2998-1. Available at:.

[3] S.C. Currall, E.B. King, N. Lane, J. Madera, S. Turner, What drives public acceptance of nanotechnology? Nat. Nanotechnol. 1 (2006) 153-155.

[4] R.I. van Giesen, A.R.H. Fischer, H.C.M. van Trijp, Changes in the influence of affect and cognition over time on consumer attitude formation toward nanotechnology: a longitudinal survey study, Publ. Understand. Sci. 27 (2018) 168-184.

[5] V. Stone, M. Führ, P.H. Feindt, H. Bouwmeester, I. Linkov, S. Sabella, F. Murphy, K. Bizer, L. Tran, M. Ågerstrand, et al., The essential elements of a risk governance framework for current and future nanotechnologies, Risk Anal. 38 (2018) 1321-1331.

[6] E. Karim, A.B. Munir, Nanotechnology: sketching the next big thing in malaysian context, Nanotechnol. Law Bus. 12 (2015) 161-172.

[7] J. Gregory, S. Miller, Science in Public: Communication, Culture, and Credibility, Perseus Publication, 1998. Available at: https://books.google.co.uk/books/abo ut/Science in_Public.html?id=FXkZRpgUk_EC\&pgis=1.

[8] E.A. Corley, Y. Kim, D.A. Scheufele, Leading US nano-scientists' perceptions about media coverage and the public communication of scientific research findings, J. Nanoparticle Res. 13 (2011) 7041-7055.
[9] C. Fraser, S. Restrepo-Estrada, Communicating for Development: Human Change for Survival, I.B Tauris and Co Ltd, London, 1998.

[10] S. Miller, Public understanding of science at the crossroads, Publ. Understand. Sci. 10 (2001) 115-120.

[11] J. Dewey, Human Nature and Conduct: an Introduction to Social Psychology, Henry Holt and Company, New York, 1922.

[12] H. Gottweis, Governing Molecules, MIT Press, Cambridge, MA, 1998.

[13] R. Hagendijk, A. Terpstra, Technology, Risk and Democracy: the Dutch Nuclear Energy Debate (1981-1984, University of Amsterdam, Amsterdam, 2004.

[14] D.S. Greenberg, Science, Money and Politics: Political Triumph and Ethical Erosion, University of Chicago Press, Chicago, 2001.

[15] D. Nelkin, Selling Science: How the Press Covers Science and Technology, Freeman and Company, New York, 1987.

[16] D. Nelkin, Changing images of science : new pressures on old stereotypes, Newsl. Progr. Public Conceptions Sci. 14 (1976) 21-31.

[17] A. Irwin, B. Wynne, Misunderstanding Science? the Public Reconstruction of Science and Technology, Cambridge University Press, 1996. Available at: http://scholar.google.com/scholar?hl=en\&btnG=Search\&q=intitle: Misunderstanding+science?\#1.

[18] R. Hagendijk, A. Irwin, Public deliberation and governance: engaging with science and technology in contemporary Europe, Minerva 44 (2006) 167-184.

[19] C.-J. Lee, D.A. Scheufele, B.V. Lewenstein, Public attitudes toward emerging technologies: examining the interactive effects of cognitions and affect on public attitudes toward nanotechnology, Sci. Commun. 27 (2005) 240-267.

[20] O. Renn, M.C. Roco, Nanotechnology and the need for risk governance, J. Nanoparticle Res. 8 (2006) 153-191.

[21] T. Rogers-Hayden, N. Pidgeon, Moving engagement "upstream"? Nanotechnologies and the royal society and royal academy of engineering's inquiry, Publ. Understand. Sci. 16 (2007) 345-364.

[22] M. Kurath, P. Gisler, Informing, involving or engaging? Science communication, in the ages of atom-, bio- and nanotechnology, Publ. Understand. Sci. 18 (2009) $559-573$.

[23] M. Kearnes, P. Macnaghten, J. Wilsdon, Governing at the Nanoscale, Demos), London, 2006.

[24] N. Pidgeon, B. Harthorn, T. Satterfield, Nanotechnology risk perceptions and communication: emerging technologies, emerging challenges, Risk Anal. 31 (2011) 1694-1700.

[25] A. Zia, A.M. Todd, Evaluating the effects of ideology on public understanding of climate change science: how to improve communication across ideological divides? Publ. Understand. Sci. 19 (2010) 743-761.

[26] M. Pilisuk, C. Acredolo, Fear of technological hazards: one concern or many? Soc. Behav. 3 (1988) 17-24.

[27] A. Boholm, Comparative studies of risk perception : a review of twenty years of research, J. Risk Res. 1 (1998) 135-163.

[28] Gallup Organization, Nuclear Power Plant, 1979. New York.

[29] E. Vaughan, B. Nordenstam, The perception of environmental risk among ethnically diverse groups, J. Cross. Cult. Psychol. 22 (1991) 26-60. Available at: http://hij.sagepub.com/cgi/doi/10.1177/1081180X03259240\%5Cn\%3CGo to IS I\%3E://WOS:000326893200002http://abs.sagepub.com/content/57/12/1650. full.pdf\%5Cnhttp://abs.sagepub.com/content/57/12/1650.full.pdf\%5Cnhttp ://onlinelibrary.wiley.com/doi/10.1111/1741-570.

[30] G.H. Brundtland, Our common future: report of the world commission on environment and development, United Nations Comm 4 (1987) 300.

[31] J. Flynn, P. Slovic, C.K. Mertz, Gender, race, and perception of environmental health risks, Risk Anal. 14 (1994) 1101-1108.

[32] M.D. Cobb, J. Macoubrie, Public perceptions about nanotechnology: risks, benefits and trust, J. Nanoparticle Res. 6 (2004) 395-405.

[33] G. Gaskell, T. Ten Eyck, J. Jackson, G. Veltri, Imagining nanotechnology: cultural support for technological innovation in Europe and the United States, Publ. Understand. Sci. 14 (2005) 81-90.

[34] M. Siegrist, C. Keller, H. Kastenholz, S. Frey, A. Wiek, Laypeople's and experts perception of nanotechnology hazards, Risk Anal. 27 (2007) 59-69.

[35] V. Sodano, M.T. Gorgitano, F. Verneau, C.D. Vitale, Consumer acceptance of food nanotechnology in Italy, Br. Food J. 118 (2016) 714-733. Available at: http://www.emeraldinsight.com/doi/10.1108/BFJ-06-2015-0226.

[36] S. George, G. Kaptan, J. Lee, L. Frewer, Awareness on adverse effects of nanotechnology increases negative perception among public: survey study from Singapore, J. Nanoparticle Res. 16 (2014) 1-11.

[37] O. Renn, E. Swaton, Psychological and sociological approaches to study risk perception, Psychol. Rev. 31 (1984) 456-462.

[38] C. Cormick, Why do we need to know what the public thinks about nanotechnology? Nanoethics 3 (2009) 167-173.

[39] A.R. Binder, M.A. Cacciatore, D.A. Scheufele, B.R. Shaw, E.A. Corley, Measuring risk/benefit perceptions of emerging technologies and their potential impact on communication of public opinion toward science, Publ. Understand. Sci. 21 (2012) 830-847.

[40] D. Brossard, D.A. Scheufele, E. Kim, V. Lewenstein, Religiosity as a perceptual filter: examining processes of opinion formation about nanotechnology, Publ. Understand. Sci. 18 (2009) 546-558.

[41] A. Retzbach, J. Marschall, M. Rahnke, L. Otto, M. Maier, Public understanding of science and the perception of nanotechnology: the roles of interest in science, methodological knowledge, epistemological beliefs, and beliefs about science, J. Nanoparticle Res. 13 (2011) 6231-6244.

[42] D.A. Scheufele, B.V. Lewenstein, The public and nanotechnology: how citizens make sense of emerging technologies, J. Nanoparticle Res. 7 (2005) 659-667. 
[43] C. Starr, Social benefit versus technological risk. What is our society willing to pay for safety? Science 165 (1969) 1232-1238, 80.

[44] P. Slovic, Perception of risk, Science 236 (1987) 280-285. Available at: htt p://www.ncbi.nlm.nih.gov/pubmed/3563507.

[45] M.F. Chen, Y.P. Lin, T.J. Cheng, Public attitudes toward nanotechnology applications in Taiwan, Technovation 33 (2013) 88-96, https://doi.org/ 10.1016/j.technovation.2012.11.008. Available at:.

[46] N. Pidgeon, B.H. Harthorn, K. Bryant, T. Rogers-Hayden, Deliberating the risks of nanotechnologies for energy and health applications in the United States and United Kingdom, Nat. Nanotechnol. 4 (2009) 95-98.

[47] J. Brown, J. Kuzma, Hungry for information: public attitudes toward food nanotechnology and labeling, Rev. Pol. Res. 30 (2013) 512-548.

[48] D.J. Bem, H.K. McConnell, Testing the self-perception explanation of dissonance phenomena: on the salience of premanipulation attitudes, J. Pers. Soc. Psychol. 14 (1970) 23-31. Available at: http://content.apa.org/journals/psp/14/1/23\% 5Cnpapers2://publication/doi/10.1037/h0020916.

[49] A.R. Pratkanis, The attitude heuristic and selective fact identification, Br. J. Soc. Psychol. 27 (1988) 257-263.

[50] M. Ross, C. Mcfarland, G.J.O. Fletcher, The effect of attitude on the recall of personal histories, J. Pers. Soc. Psychol. 40 (1981) 627-634.

[51] J. Besley, Current Research on Public Perceptions of Nanotechnology. Emerg. Health Threats J. 3, 2010, p. e8. Available at: http://www.pubmedcentral.nih.go $\mathrm{v} /$ articlerender.fcgi? artid $=3167657 \&$ tool $=$ pmcentrez\&rendertype $=$ abstract.

[52] D. Bennet-Woods, in: M.T. Burke, G.L. Hornyak, D. Bennet-Woods, J.A. Shatkin, P.M. Bouche (Eds.), Nanotechnology: Ethics and Society, Taylor \& Francis Group, New York, 2008.

[53] M. Douglas, Cultural bias, R. Anthropol. Inst., 1978, p. 302. Available at: http ://www.itto.or.jp/live/PageDisplayHandler?pageId=270.

[54] S. Oltedal, B. Moen, H. Klempe, T. Rundmo, Explaining Risk Perception: an Evaluation of Cultural Theory, 2004.

[55] J. Tansey, T. O'Riordan, Cultural theory and risk: a review, Health Risk Soc. 1 (1999) 71-90.

[56] V. Mamadouh, Grid-group cultural theory: an introduction, Geojournal 47 (1999) $395-409$.

[57] J. Zhang, G. Wang, D. Lin, High support for nanotechnology in China: a case study in Dalian, Sci. Publ. Pol. 43 (2016) 115-127.

[58] J.O. Baker, Public perceptions of incompatibility between "science and religion, Publ. Understand. Sci. 21 (2012) 340-353.

[59] D.A. Scheufele, E.A. Corley, T. Shih, K.E. Dalrymple, S.S. Ho, Religious Beliefs and Public Attitudes toward Nanotechnology in Europe and the United States, vol. 4, 2009, pp. 91-94.

[60] D.S. Hope, P.E. Petersen, A proposal to advance understanding of nanotechnology's sosial impact, in: M.C. Roco, W.S. Bainbridge (Eds.), Nanotechnology: Societal Implications Individual Perspectives, National Science Foundation, 2007, pp. 109-113. Available at: http://www.wtec.org/SocietalImp lications/2/si2vii_report.pdf.

[61] J. Conti, T. Satterfield, B.H. Harthorn, Vulnerability and social justice as factors in emergent U. S. Nanotechnology risk perceptions, Risk Anal. 31 (2011) 1734-1748.

[62] T. Saidi, Perceived risks and benefits of nanomedicine : a case study of an antituberculosis drug, Glob. Heal. Innov. 1 (2018) 1-7.

[63] M. Siegrist, G. Cvetkovich, C. Roth, Salient value similarity, social trust, and risk/ benefit perception salient, Risk Anal. 20 (2000) 353-362.

[64] S.C. Currall, New insights into public perceptions, Nat. Nanotechnol. 4 (2009) 79-80.

[65] Department of Statistics Malaysia, Malaysian Population Statistics, 2017.

[66] A. Kishimoto, Public Perception of Nanotechnologies in Japan from 2005 to 2009, 2010 (Japan).

[67] A. Collins, The ethnic security dilemma: evidence from Malaysia, Contemp. S. Asia 20 (1998) 261-278.

[68] K.A. McComas, J.C. Besley, Fairness and nanotechnology concern, Risk Anal. 31 (2011) 1749-1761.

[69] J.V. Field, G.E. Schreer, Age differences in personal risk perceptions: a note on an exploratory descriptive study, Risk Health Saf. Environ. 11 (2000). Available at: http://heinonline.org/HOL/Page?handle=hein.journals/risk11\&id=299\&div $=$ \& collection $=$ journals.

[70] B. Fischhoff, P. Slovic, S. Lichtenstein, "The Public" vs."The Expert": perceived vs actual disagreements about risks of nuclear power, Adv. Risk Anal. 1 (1981).

[71] M. Po, J.D. Kaercher, B.E. Nancarrow, Literature review of factors influencing public perceptions of water reuse, CSIRO L. Water Tech. Rep. 54 (2003) 1-44.

[72] A. Grinbaum, Cognitive barriers in perception of nanotechnology, J. Law Med. Ethics 34 (2006) 689-694.

[73] A. Capon, J. Gillespie, M. Rolfe, W. Smith, Comparative analysis of the labelling of nanotechnologies across four stakeholder groups, J. Nanoparticle Res. 17 (2015) 1-13.

[74] M. Siegrist, C. Keller, Labeling of nanotechnology consumer products can influence risk and benefit perceptions, Risk Anal. 31 (2011) 1762-1769.

[75] H. van Dijk, A.R.H. Fischer, H.J.P. Marvin, H.C.M. van Trijp, Determinants of stakeholders' attitudes towards a new technology: nanotechnology applications for food, water, energy and medicine, J. Risk Res. 20 (2017) 277-298.
[76] D.A. Scheufele, A. Dudo, Emerging agendas at the intersection of political and science communication the case of nanotechnology, Ann. Int. Commun. Assoc. 34 (2010) 143-167.

[77] G. Gardner, G. Jones, A. Taylor, J. Forrester, L. Robertson, Students' risk perceptions of nanotechnology applications : implications for science education, Int. J. Sci. Educ. 32 (2010) 1951-1969.

[78] L.J. Frewer, N. Gupta, S. George, A.R.H. Fischer, E.L. Giles, D. Coles, Consumer attitudes towards nanotechnologies applied to food production, Trends Food Sci. Technol. 40 (2014) 211-225, https://doi.org/10.1016/j.tifs.2014.06.005. Available at:.

[79] N. Gupta, A.R.H. Fischer, L.J. Frewer, Ethics, risk and benefits associated with different applications of nanotechnology: a comparison of expert and consumer perceptions of drivers of societal acceptance, Nanoethics 9 (2015) 93-108.

[80] S.F. Lin, H. Shyang Lin, Y.Y. Wu, Validation and exploration of instruments for assessing public knowledge of and attitudes toward nanotechnology, J. Sci. Educ. Technol. 22 (2013) 548-559.

[81] G. Stoker, W. Jennings, M. Evans, M. Halupka, The impact of anti-politics on policymaking : does lack of political trust matter?, Glasgow, in: UK Political Studies Association Conference, 2017, pp. 1-26.

[82] J. Macoubrie, Informed public perceptions of nanotechnology and trust in government, Available at: http://scholar.google.com/scholar? $\mathrm{hl}=$ en \&btn $\mathrm{G}=$ Search \& $\mathrm{q}=$ intitle:Informed + Public + Perceptions + of + Nanotech nology+and+Trust+in+Government\#0, 2005.

[83] R. Rothwell, H. Wissema, Technology, culture and public policy, Technovation 4 (1986) 91-115.

[84] S.J. Conroy, T.L.N. Emerson, Ethics and religion: as a predictor of religiosity business ethical awareness students, J. Bus. Ethics 50 (2004) 383-396.

[85] G. Magill, Theology in business ethics: appealing to the religious imagination, J. Bus. Ethics 11 (1992) 129-135.

[86] A.R. Chapman, Unprecedented Choices: Religious Ethics at the Frontier of Genetic Science, Fortress Press, Minneapolis, 1999.

[87] M.E. Karim, S. Akhter, A.B. Munir, F. Muhammad-Sukki, K.E. Hoque, S.H. Mohd Yasin, S.S. Abu-Bakar, S.H. Abu-Bakar, N.A. Bani, A.V. Wirba, et al., Malaysian tertiary level students and their understanding, knowledge and perception of nanotechnology, J. Adv. Res. Soc. Behav. Sci. 6 (2017) 52-67. Available at: http ://www.akademiabaru.com/doc/ARSBSV6_N1_P52_67.pdf.

[88] R. Burri, Coping with uncertainty: assessing nanotechnologies in a citizen panel in Switzerland, Publ. Understand. Sci. 18 (2009) 498-511.

[89] G. Forloni, Responsible nanotechnology development, J. Nanoparticle Res. 14 (2012) 1-17.

[90] E. Kelechukwu, Social, legal, ethical, health, safety and environmental aspects of nanotechnology, Available at: http://www.academia.edu/26150828/SOCIAL_L EGAL_ETHICAL_HEALTH_SAFETY_AND_ENVIROMENTAL_ASPECTS_OF_NANOT ECHNOLOGY, 2016.

[91] L.A. Reisch, G. Scholl, S. Bietz, "Better safe than sorry": consumer perceptions of and deliberations on nanotechnologies, Int. J. Consum. Stud. 35 (2011) 644-654.

[92] M.D. Cobb, Creating informed public opinion: citizen deliberation about nanotechnologies for human enhancements, J. Nanoparticle Res. 13 (2011) 1533-1548.

[93] K.L. Kjølberg, Representations of nanotechnology in Norwegian newspapers implications for public participation, Nanoethics 3 (2009) 61-72.

[94] A. Carvalho, J.A. Nunes, Assembling upstream Engagement : the case of the Portuguese deliberative forum on nanotechnologies, Nanoethics 12 (2018).

[95] A. Irwin, Citizen Science. A Study of People, Expertise and Sustainable Development First Edit, London: Routledge, 1995. Available at: http://oss. sagepub.com/cgi/doi/10.1177/017084069701800109.

[96] T. Rogers-hayden, A. Mohr, N. Pidgeon, Introduction: engaging with nanotechnologies - engaging differently? Nanoethics 1 (2007) 123-130.

[97] S.H. Cutcliffe, C.M. Pense, Framing the discussion: nanotechnology and the social construction of technology - what STS scholars are saying, Nanoethics 6 (2012) 81-99.

[98] R.V. Burri, Models of public engagement: nanoscientists' understandings of science - society interactions, Nanoethics 12 (2018).

[99] S. Yuan, J.C. Besley, A. Dudo, A comparison between scientists' and communication scholars' views about scientists' public engagement activities, Publ. Understand. Sci. 1 (2018). Available at: http://journals.sagepub.com/doi/1 $0.1177 / 0963662518797002$.

[100] M. Powell, D. Lee Kleinman, Building citizen capacities for participation in nanotechnology decision-making: the democratic virtues of the consensus conference model, Publ. Understand. Sci. 17 (2008) 329-348.

[101] C. Cormick, S. Hunter, Valuing values: better public engagement on nanotechnology demands a better understanding of the diversity of publics, Nanoethics 8 (2014).

[102] N.A. Kamarulzaman, K.E. Lee, K.S. Siow, M. Mokhtar, Psychological and socilogical perspectives for good governance of sustainable nanotechnology development in Malaysia, J. Nanoparticle Res. 21 (2019) 1-21.

[103] N.A. Kamarulzaman, K.E. Lee, K.S. Siow, Public perception of nanotechnology for good governance: a conceptual framework for psychological and sociological approaches, J. Food Agric. Environ. 16 (2018) 168-174. 